\title{
Robust Localization for Robot and IoT Using RSSI
}

\author{
Youngchul Bae ${ }^{\circledR}$ \\ Division of Electrical, Electronic communication and Computer Engineering, Chonnam National University, \\ Yeosu 59626, Korea; ycbae@chonnam.ac.kr; Tel.: +82-10-8996-6839
}

Received: 24 April 2019; Accepted: 6 June 2019; Published: 11 June 2019

\begin{abstract}
Node-localization technology has been supported in the wireless sensor network (WSN) environment. Node localization is based on a few access-point (AP) nodes that comprises positioning information because they are fixed, and a beacon node that comprises unknown positioning information because it is moving. To determine the position of the unknown node, it must use two or three APs that comprise certain positioning information. There are a number of representative range-based methods, including time of arrival (TOA), weighted centroid locating algorithm, received signal strength intensity (RSSI), and time difference of arrival (TDOA) signal, that are received by the receiver. The RSSI method has its advantages. A simple device structure means that the RSSI method is easy to use. Because the structures of previous wireless local area network (LAN) technologies make them compatible with RSSI information, the RSSI method is widely used in the related area of position tracking. In addition, this algorithm has a hardware system that cannot be increased, has the advantage of the miniaturization of the node, and can wear through obstacles. This paper proposes the application of a robust ranging method that can be applied in robots and Internet of Things (IoT) using RSSI, especially in the tracing location of each nursing home patient, where the RSSI method with trilateral technique is used. This paper shows the results of the measured point from the application of the trilateral technique, and it also represents the results of the error distance between the ideal point and the measured point using computer simulation. Finally, this paper presents an estimation of localization using a real experimental device with a BLE (Bluetooth low-energy) transmitter and receiver, and beacon gateway, by applying an RSSI algorithm with the trilateral technique.
\end{abstract}

Keywords: node localization; RSSI; IoT; robot; received signal strength intensity

\section{Introduction}

Recently, the Internet of Things (IoT) has focused on fields such as research and business, which include information communication technology (ICT), traffic systems, military and defense systems, robot systems [1-4], and wireless sensor networks (WSNs) [5-8].

Among the IoT and robot technologies, one of the key technologies requires localization [9-12] of humans or robots by using sensors or other devices. This technique has been called "node localization" or just "localization". Generally, node localization requires real time to confirm a node's location; therefore, a real-time locating system (RTLS) that searches for node locations in real time is typically used to identify the locations of sensors, objects, robots, and humans. Most RTLSs that are released onto the market are used with wireless communication technology of a $2.45 \mathrm{GHz}$-frequency bandwidth that is applicable for an active radio-frequency-identification (RFID) system.

The node-localization technology has been supported in a WSN context. In recent years, research on node-localization problems has been more extensive, in accordance with the progress of IoT technologies. Generally, nodes are divided into beacon or access point (AP) nodes, and unknown node (beacon) and the known node (AP). Node localization is based on several AP nodes that contain 
positioning information because they are fixed, and a beacon node that contains unknown positioning information because it is moving. To determine the position of the unknown node, two or three APs that comprise certain positioning information must be used.

Typically, the following three significant algorithms have been used for localization: range-based [13-23], range-free [24], and the fusion of a range-free and range-based [25]. In order to calculate the node location, this paper focuses on the range-based algorithm.

The range-based algorithm is defined by protocols that use absolute point-to-point distance estimates of the distance or angle between beacon and AP. The range-free algorithm focuses on a more cost-effective method than range-based algorithms, because it does not need to assume the availability or validity of information. The fusion algorithms consist of the integration of the range-based and range-free algorithms. However, this algorithm has the complication of having to calculate the localization, compared with the range-free or the range-based algorithms.

There are a number of representative range-based methods, including time of arrival (TOA) [16-19], received signal strength intensity (RSSI) [20,21], weighted centroid-locating algorithm [22], time difference of arrival (TDOA) [23], angle of arrival (AOA) [24], phase of arrival (POA) [25], and so on [26].

TOA uses the propagation time that is taken between the transmitter and the receiver. The TOA has some advantages such as having a simple algorithm, easy implementation, and accurate localization. In addition, it also has disadvantages: it has to maintain the clock synchronization between the transmitting and receiving devices, it is affected by the multipath effect, and it needs a sound wave transceiver. In order to obtain the time that is taken to transfer a signal between the tag and the AP in the TOA method, a time-synchronization match needs to occur. However, such a match is difficult to attain. To match the time synchronization, the simple network time protocol (SNTP) must typically be applied. When this protocol is applied to the TOA method, the time synchronization can be matched for the APs; however, this is impossible for tagging. Because the precision of the AP time synchronization is as low as 1 second, this method is limited to the time synchronization for the localization of short distances.

TDOA applies the flight-time difference to a radio wave. The TDOA algorithm has very accurate localization performance, especially in the outside building, and also it does not require accurate clock synchronization between a transmitting and a receiving device. However, this algorithm has some problems, for example, it is affected by multipath effects like TOA, it needs to use an ultrasonic transceiver, and it depends upon the condition of the ultrasonic wave propagation distance. Further, another disadvantage of the TDOA is that many computations are required to calculate its time differences.

To achieve a solution for the time-synchronization problem in the TOA and TDOA methods, numerous methods have been proposed by many researchers [26]. These methods measure the difference between the transfer time between the tag and the AP, and transform-distance time. The TDOA requires a matching of the time synchronization only for the AP and not for the tag. However, a technique needs to be developed for the TDOA method to match the high precision of the time synchronizations for all of the APs.

The weighted centroid-locating algorithm reflects the size of the reference node's decision on the centroid coordinate, and uses the weighting factor to reflect the influence of each reference node on the position of the centroid, reflecting their intrinsic relationship. This method has some advantages such as small communication overhead, low hardware requirements, and being suitable for sensor node processing. However, it also has some disadvantages, which include the fact that connectivity to the network demand is higher than for the other algorithm, and the required density of the beacon node is very large.

The AOA and the POA apply in the angle and the phase of arrival, respectively, to a radio wave. AOA and POA algorithms also have accurate localization performances that are similar to TDOA or TOA, and they can also provide precise location information. Nevertheless, these are vulnerable to 
external environment influences, which require an ultrasonic transceiver. They are not suitable for a large-scale network because their power consumption is considerable.

The RSSI [27-31] is used to measure the strength intensity of the signal that is received by the receiver. There are also advantages to the RSSI method. A simple device structure means that the RSSI method is easy to use compared to other techniques such as TOA, TDOA, AOA, and POA. Because the structures of previous wireless local area network (LAN) technologies make them compatible with RSSI information, the RSSI method is widely used in the related area of position tracking. In addition, this algorithm has a hardware system that cannot be increased, the advantage of the miniaturization of the node, and can wear through obstacles. Regarding the disadvantages of the RSSI method, the accuracy of a position estimation that is made by using RSSI varies according to the accuracy of the RSSI measurements and the circumstances that are obtained from a real mobile device. Therefore, the stability of the measured RSSI value is dependent upon the corresponding circumstances, and the value could be unstable. For instance, when the RSSI value between a directional-antenna tag and an AP is measured, the quality of an office partition or the wall material, and any obstacles that exist between the transmitter and the receiver such as a wall, column, furniture, or human, can significantly affect the signal-loss path. An RSSI positioning estimation also provides relatively low levels of accuracy and security.

Like the RSSI method, the TOA and TDOA methods may cause errors according to the propagation environment. The main cause of an error is multipath fading, and that occurs because there is no security for the line of sight (LOS). However, this error is not larger than the RSSI error, and the method has been proposed to solve this problem [16].

Table 1 shows the comparison of root mean square (RMS) error value after this paper tested each algorithm, including the weighted centroid-locating algorithm, the RSSI locating algorithm, and the TOA-locating algorithm, with 3 nodes for 6 times and 100 times by computer simulation. Particularly, the case of the RSSI-locating algorithm used $10 \mathrm{~mW}$ transmit power.

Table 1. Comparison with root mean square (RMS) error value for the weighted centroid-locating algorithm, received signal strength intensity (RSSI), and time of arrival (TOA)- locating algorithm.

\begin{tabular}{|c|c|c|c|c|c|c|c|}
\hline \multirow{2}{*}{ Algorithm } & \multicolumn{5}{|c|}{ Error (m) } & \multirow{2}{*}{$\begin{array}{l}6 \text { times } \\
\text { RMS (m) }\end{array}$} & \multirow{2}{*}{$\begin{array}{c}100 \text { times } \\
\text { RMS }\end{array}$} \\
\hline & 1 & 2 & 3 & 4 & 5 & & \\
\hline $\begin{array}{c}\text { Weighted } \\
\text { Centroid-locating } \\
\text { algorithm [22] }\end{array}$ & 4.4283 & 4.1263 & 2.2145 & 7.5029 & 6.985 & 5.40 & 5.29 \\
\hline $\begin{array}{l}\text { RSSI locating } \\
\text { algorithm [20] }\end{array}$ & 2.3065 & 1.7712 & 4.1526 & 3.1047 & 1.1119 & 2.70 & 1.97 \\
\hline $\begin{array}{l}\text { TOA-locating } \\
\text { algorithm [19] }\end{array}$ & 0.2154 & 0.1130 & 0.2444 & 1.1266 & 0.1121 & 0.17 & 0.12 \\
\hline
\end{tabular}

From Table 1, we know the RMS error value of TOA-locating algorithm is the smallest. However, it is difficult to match the TOA-locating algorithm with the time synchronization, so it is not easy to implement in the field. Even though the RMS error value of RSSI is bigger than TOA, RSSI is easy to implement in the real field without increasing hardware system. Therefore, this paper proposes the application of a robust ranging method that can be applied in the robot, IoT, and especially in tracing location of each patient of a nursing home by using the RSSI method. This paper shows the result of the measured point from the application of the trilateral technique, and this paper also represents the result of the error distance between the ideal point and the measured point by computer simulation. Finally, this paper presents an estimation of localization by an experimental device with a BLE (Bluetooth low-energy) transmitter and receiver, and a beacon gateway by applying the RSSI algorithm with the trilateral technique that is presented in computer simulation. 


\section{Ranging with RSSI Method}

\subsection{Signal-Propagation Model}

The RSSI-based distance-measurement method involves the utilization of the signal-strength intensity of wireless mobile technology. This is a technique that connects signals to moving distances for the signal-power loss or signal-path loss between the tag and AP.

The free-space model has been utilized in WSNs as the most common signal-propagation model. This paper assumed that the receiver in the communication radius can receive the data in the free-space model; in this case, it can obtain the distance of the node from another node through the measurement of the received signal strength of the incoming radio signal.

Figure 1 shows the simplest form of the basic power transfer between a transmitter and a receiver in an antenna with distance $r$.

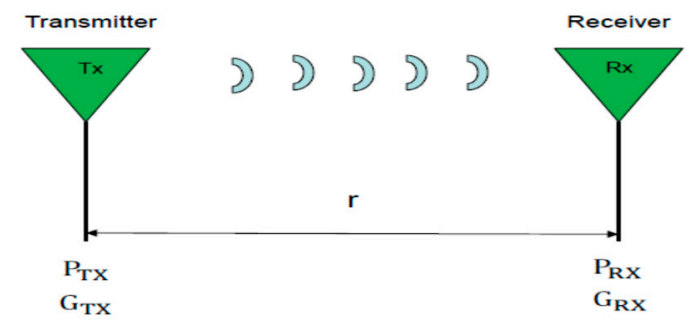

Figure 1. Basic power transfer between transmitter and receiver of antenna.

Using Figure 1 as a basis, the relationship between the received power and the transmitted power through Equation (1) can be described, which was proposed by Friis [32], as follows:

$$
P_{R X}=P_{T X} G_{T X} G_{R X}\left(\frac{\lambda}{4 \pi r}\right)^{2}(\mathrm{dBm})
$$

where, $P_{R X}, P_{T X}, G_{T X}$, and $G_{R X}$ are the received power at the receiver, the transmission power of the sender, transmitter gain, and the receiver for a mobile device or tag, respectively. $\lambda$ is wavelength and $r$ is the separated distance between the mobile device or the tag of the receiver and the transmitter. This paper assumed that $G_{T X}=1$ and $G_{R X}=1$ in the embedded device.

From Equation (1), with Friis's free-space-transmission equation, it is possible to recognize that the detected signal strength in the receiver decreases in a quadratic form in accordance with the distance to the sender.

\subsection{Power Law Model}

An embedded system cannot directly apply Equation (1), because Equation (1) is not considered a non-line-of sight (NLOS) environment. To apply an embedded system with empirical experience, a new path-loss formula that is modified from Equation (1) needs to made. This could derive the relationship between the path loss $\left(P_{L}\right)$ and the distance $(r)$ for the signal according to the following Equation (2):

$$
P_{L}=20 \log _{10}\left(\frac{4 \pi r}{\lambda}\right)(\mathrm{dBm})
$$

Equation (2) can be represented by Equation (3), as follows:

$$
P_{L}=A \cdot \log _{10}(r)+B(\mathrm{dBm})
$$

Here, coefficient $A$ and coefficient $B$ are decided by the environment and frequency bandwidth for the use of the system; therefore, it is important to find the propagation model by using the RSSI in a localization system or a position-tracking system. The performance of either system depends 
on the way that coefficient $A$ and coefficient $B$ are decided from the Equation (3). In some instances, iEquation (4) or Equation (5) can be chosen to decide the polynomial coefficients, as follows:

$$
\begin{gathered}
P_{L}=A \cdot \log _{10}(r)+B \cdot r+C(\mathrm{dBm}) \\
P_{L}=A \cdot r^{3}+B \cdot r^{2}+C \cdot d+D(\mathrm{dBm})
\end{gathered}
$$

Although any propagation model can be used, it is not easy to overcome the RSSI method with the variety of propagation effects that exist.

\subsection{Position Estimation with Trilateral Technique}

Generally, in order to find the unknown node in the sensor node of the localization process, the distance from the AP to the unknown, adjacent beacon node needs to be calculated. This paper also needs to compute the relative angle between the AP and the unknown node as a moving device.

Typically, three algorithms - the trilateral technique, the triangulation technique, and the maximum-likelihood technique-are used to calculate the distance to the unknown node, and these techniques have been used in the field. Because the triangulation technique has large angle error and the maximum-likelihood technique has complex calculation process, generally, trilateral technique is used to calculate the distance to the unknown node. Therefore, this paper only focuses on trilateral technique.

Figure 2 shows the trilateral technique [20]. The coordinates of the three nodes (A, B, and C) are known as $\left(x_{a}, y_{a}\right),\left(x_{b}, y_{b}\right)$, and $\left(x_{c}, y_{c}\right)$, respectively. $d_{a}, d_{b}$, and $d_{c}$ are shown as the distances from the three known nodes, A, B, and C, respectively, to the unknown node D.

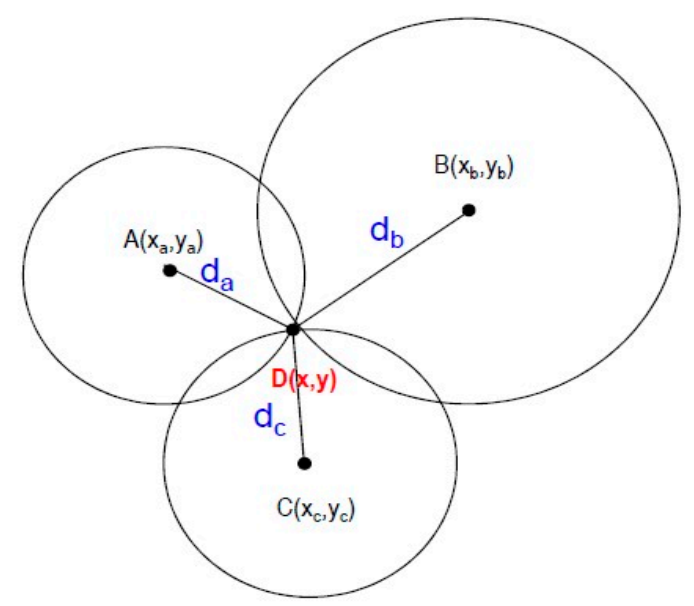

Figure 2. Trilateral measurement method.

The coordinates of the unknown node are assumed as $\mathrm{D}(\mathrm{x}, \mathrm{y})$. It obtained three distances $\left(d_{a}, d_{b}\right.$, and $d_{c}$ ) from the nonlinear system of equations using Equations (6)-(8), as follows:

$$
\begin{aligned}
& d_{a}=\sqrt{\left(x-x_{a}\right)^{2}+\left(y-y_{a}\right)^{2}}(\mathrm{~m}) \\
& d_{b}=\sqrt{\left(x-x_{b}\right)^{2}+\left(y-y_{b}\right)^{2}}(\mathrm{~m}) \\
& d_{c}=\sqrt{\left(x-x_{c}\right)^{2}+\left(y-y_{c}\right)^{2}}(\mathrm{~m})
\end{aligned}
$$

Using a linearization method, this paper obtained the coordinates of point D from Equation (9), as follows:

$$
\left[\begin{array}{l}
x \\
y
\end{array}\right]=\left[\begin{array}{ll}
2\left(x_{a}-x_{c}\right) & 2\left(y_{a}-y_{c}\right) \\
2\left(x_{b}-x_{c}\right) & 2\left(y_{b}-y_{c}\right)
\end{array}\right]^{-1}\left[\begin{array}{c}
x_{a}{ }^{2}-x_{c}{ }^{2}+y_{a}{ }^{2}+d_{c}{ }^{2}-d_{a}{ }^{2} \\
x_{b}{ }^{2}-x_{c}{ }^{2}+y_{b}{ }^{2}+d_{c}{ }^{2}-d_{b}{ }^{2}
\end{array}\right]
$$




\section{Simulation Using RSSI with the Trilateral Technique}

\subsection{RSSI Algorithm}

This section discusses the computer simulation where the RSSI is used with the trilateral technique. Generally, radio signals are affected by a loss of energy intensity during the transmission from the node to the AP. A loss of energy intensity, as well as a radio-signal propagation distance, is in line with the corresponding mathematical relationship. The RSSI is the localization of the reference nodes, and takes advantage of this node of communication between the measurement distances. The radio-signal strength is reduced in accordance with the increase of the propagation distance during the transmission process; this is based on the AOA method diagram that is shown in Figure 3, as follows:

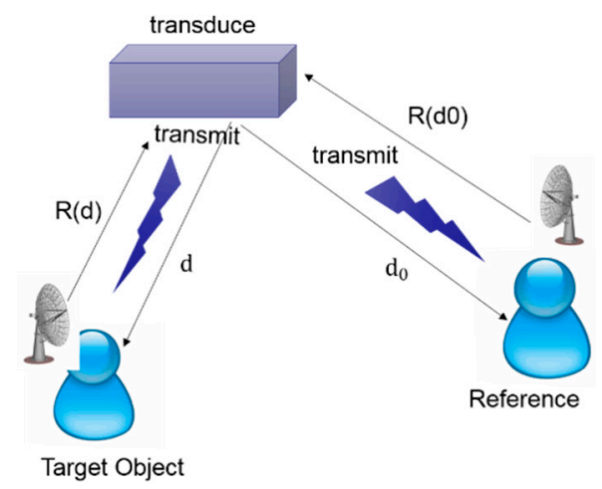

Figure 3. Received Signal Strength Intensity (RSSI) model.

The communication distance and the relational expression of the radio-signal strength is derived next, as shown in the following Equation (10):

$$
R S S I=R(d)-R\left(d_{0}\right)-10 n \log \left(\frac{d}{d_{0}}\right)(\mathrm{dBm})
$$

where $d$ is the distance between a target and a transducer, $d_{0}$ is a distance between a reference and transducer, and $R(d)$ and $R\left(d_{0}\right)$ are the radio-signal strength of the target and the radio-signal strength of the reference, respectively.

Using Equation (10) as a basis, it can therefore measure the signal strength of the RSSI between the target and the reference node, and then signal strength can be obtained regarding the communication distance $\mathrm{d}$ between the target and the reference node.

The RSSI principle is simple, and in terms of wireless transmitting, other auxiliary hardware does not need to be added to the receiving node. Furthermore, the cost is low. The RSSI is therefore used for the indoor localization for the tracing location of each nursing home patient.

\subsection{Computer Simulation}

Using Equations (9) and (10), this paper performed a computer simulation to determine the location for the tracing location of each nursing home patient. Figure 4 shows the flow chart for computing localization process of the robot and IoT sensor. To reflect the real environment of hospital and building for computer simulation, researchers should consider the signal that can interfere with noise, signal reflection, diffraction, and so on when setting the noise factor of flow chart, as shown in Figure 4.

For the computer simulation using RSSI, the size of space environment assumes $30 \mathrm{~m} \times 30 \mathrm{~m}$. Figures 5-12 are shown in the results of computer simulation for localization of robot or IoT sensors. The red, blue, and green line with circle $(\bigcirc)$ represents base point 1 , base point 2 , and base point 3 , respectively. The black and red line with asterisk $\left({ }^{*}\right)$ displays location point of ideal and real position, respectively. 


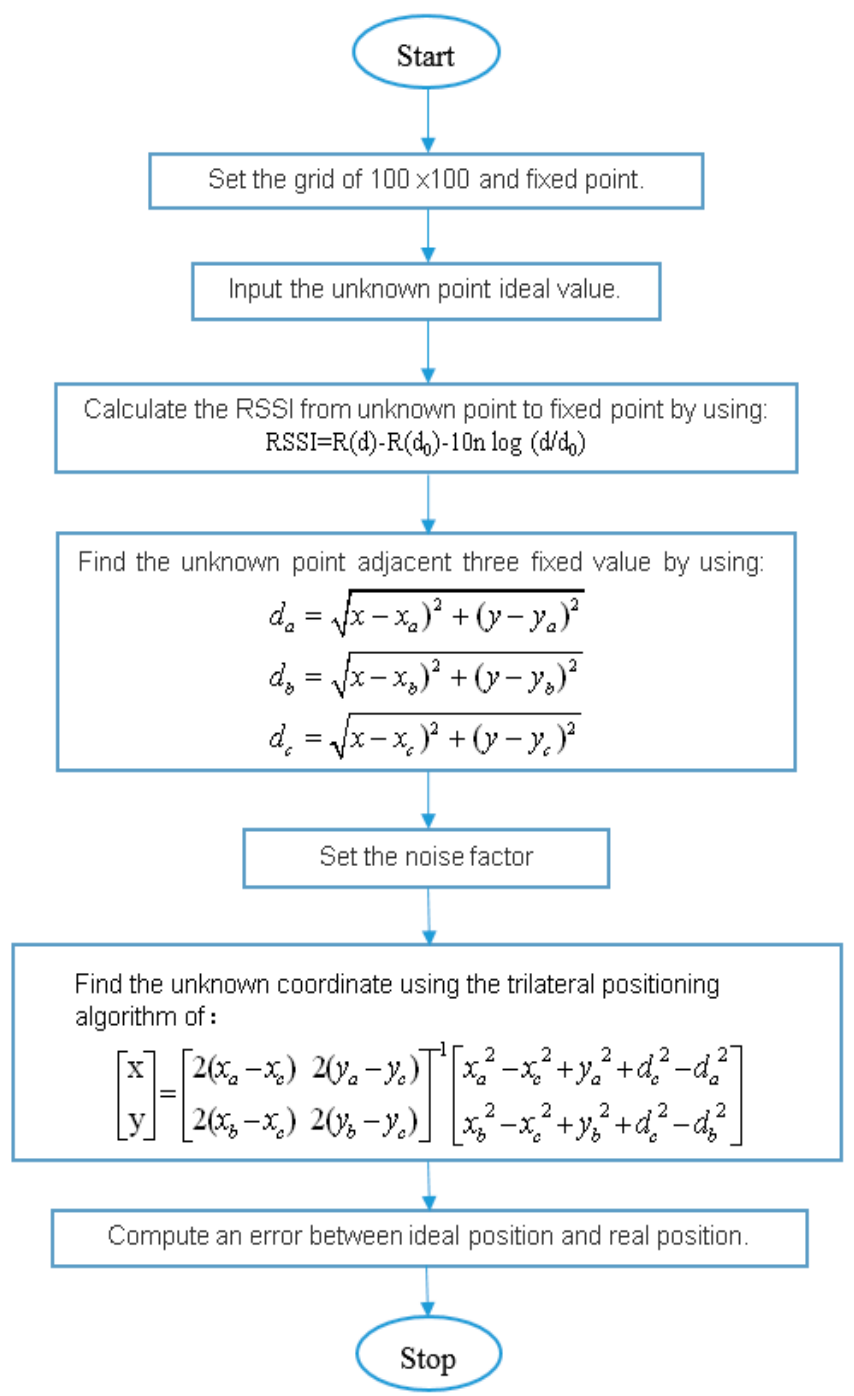

Figure 4. Flow chart for computing the localization of robot or internet of things (IOT) sensor.
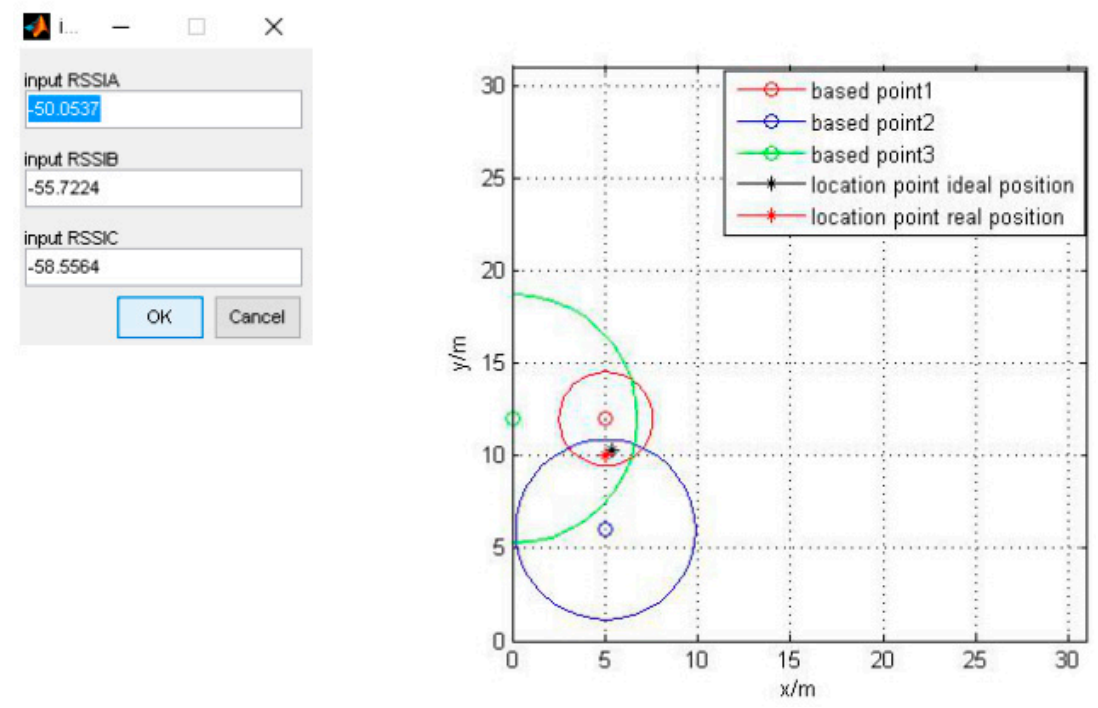

Figure 5. Simulation result when the RSSI values are $-50.0537,-55.7224$, and $-58.5564(\mathrm{dBm})$ for the three points $(a, b$, and $c)$. 

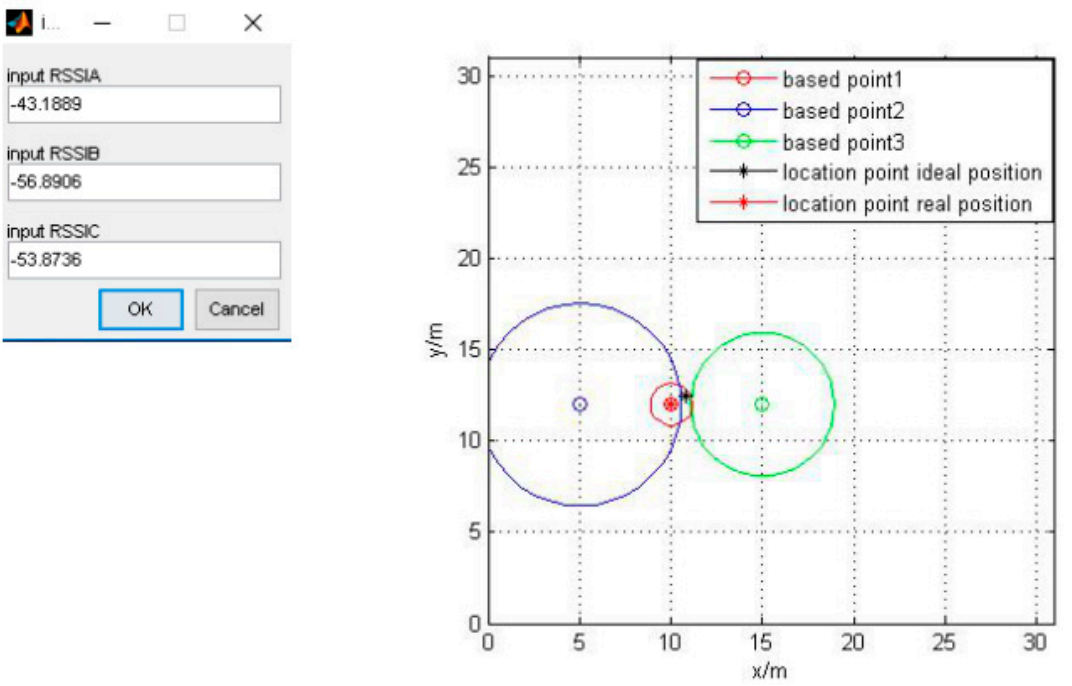

Figure 6. Simulation result when the RSSI values are $-43.1889,-56.8906$, and $-53.8736(\mathrm{dBm})$ for the three points $(a, b$, and $c)$.

\begin{tabular}{l}
\hline i... \\
input RSSIA \\
-54.1075 \\
input RSSIB \\
-52.4424 \\
input RSSIC \\
$-58.2356 \quad \square$ \\
$\qquad$ OK Cancel \\
\hline
\end{tabular}

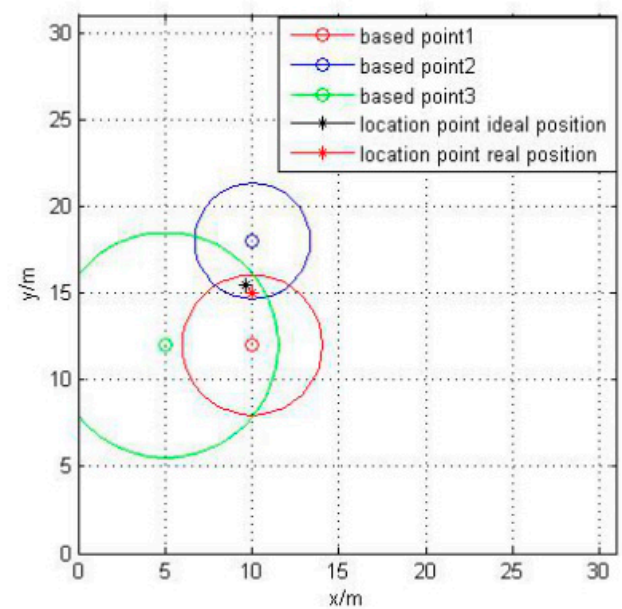

Figure 7. Simulation result when the RSSI values are $-54.1075,-52.4424$, and $-58.2356(\mathrm{dBm})$ for the three points $(a, b$, and $c)$.
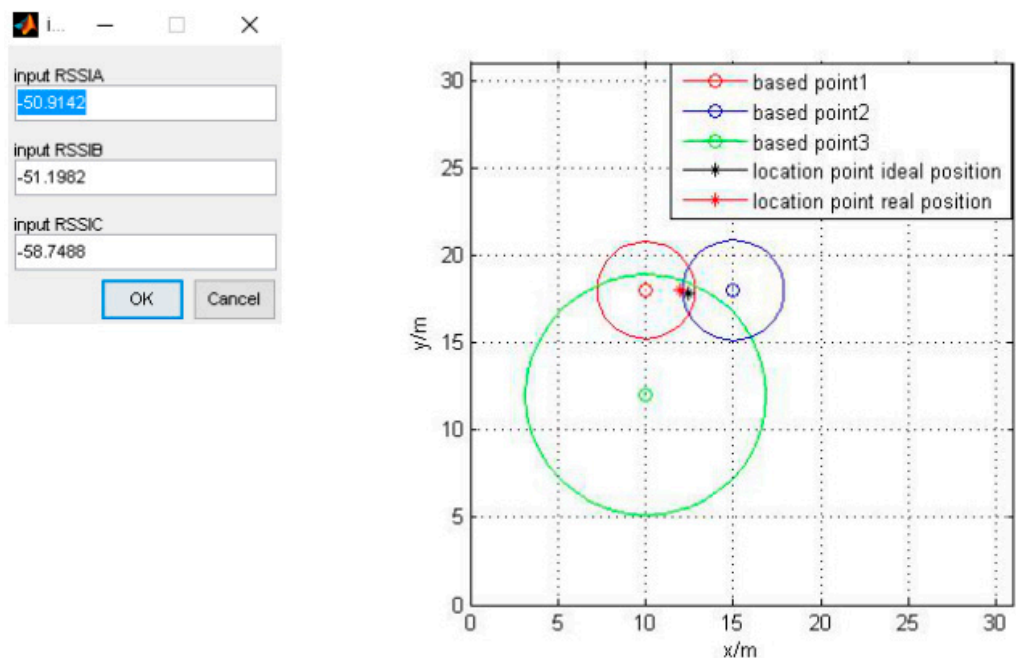

Figure 8. Simulation result when the RSSI values are $-50.9142,-51.1982$, and $-58.7488(\mathrm{dBm})$ for the three points $(a, b$, and $c)$. 

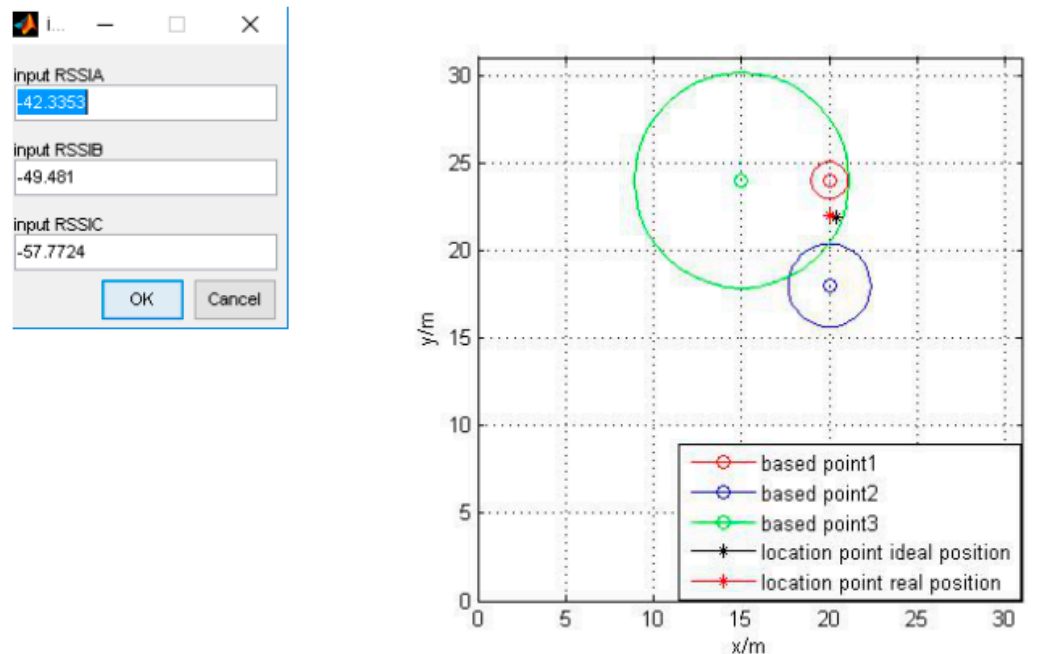

Figure 9. Simulation result when the RSSI values are $-42.3353,-49.481$, and $-57.7724(\mathrm{dBm})$ for the three points $(a, b$, and $c)$.
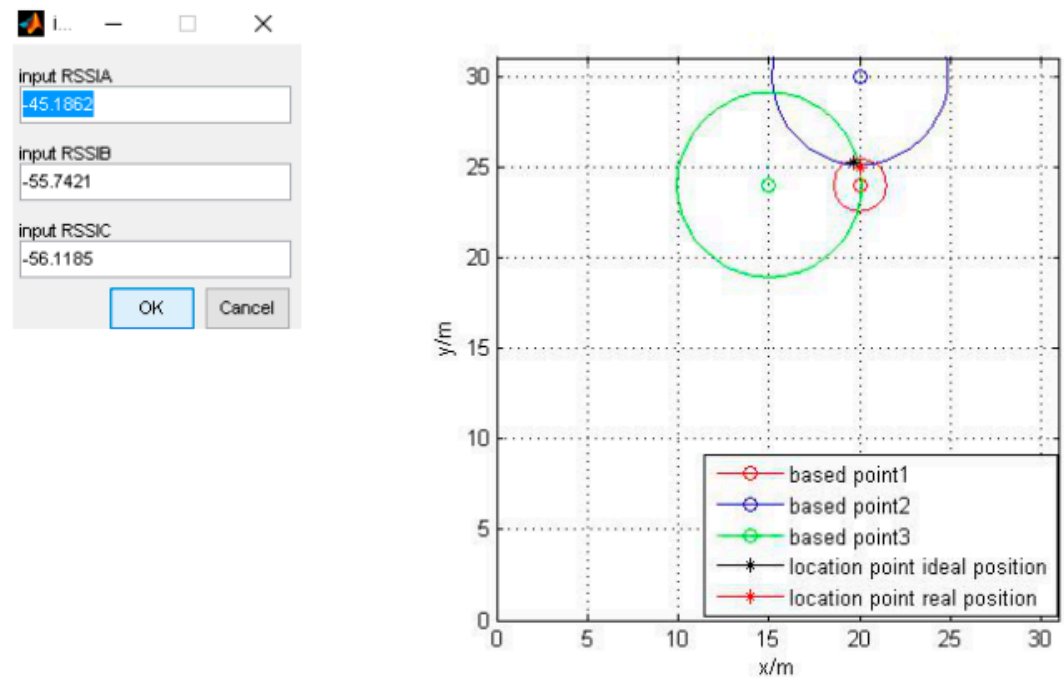

Figure 10. Simulation result when the RSSI values are $-45.1862,-55.7421$, and $-58.1185(\mathrm{dBm})$ for the three points $(a, b$, and $c)$.
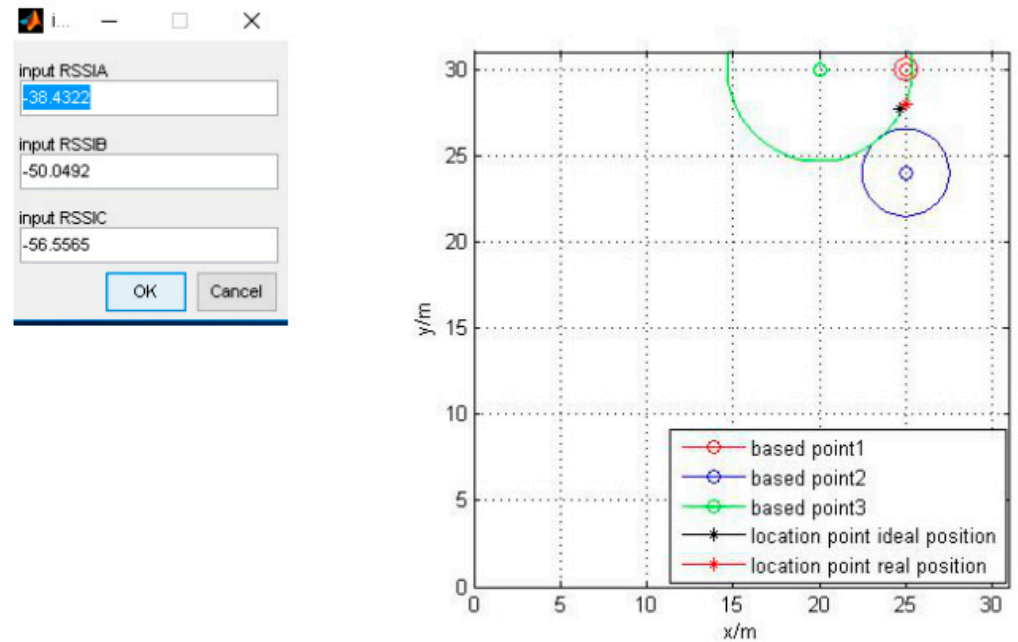

Figure 11. Simulation result when the RSSI values are $-38.4322,-50.0492$, and $-58.5565(\mathrm{dBm})$ for the three points $(a, b$, and $c)$. 

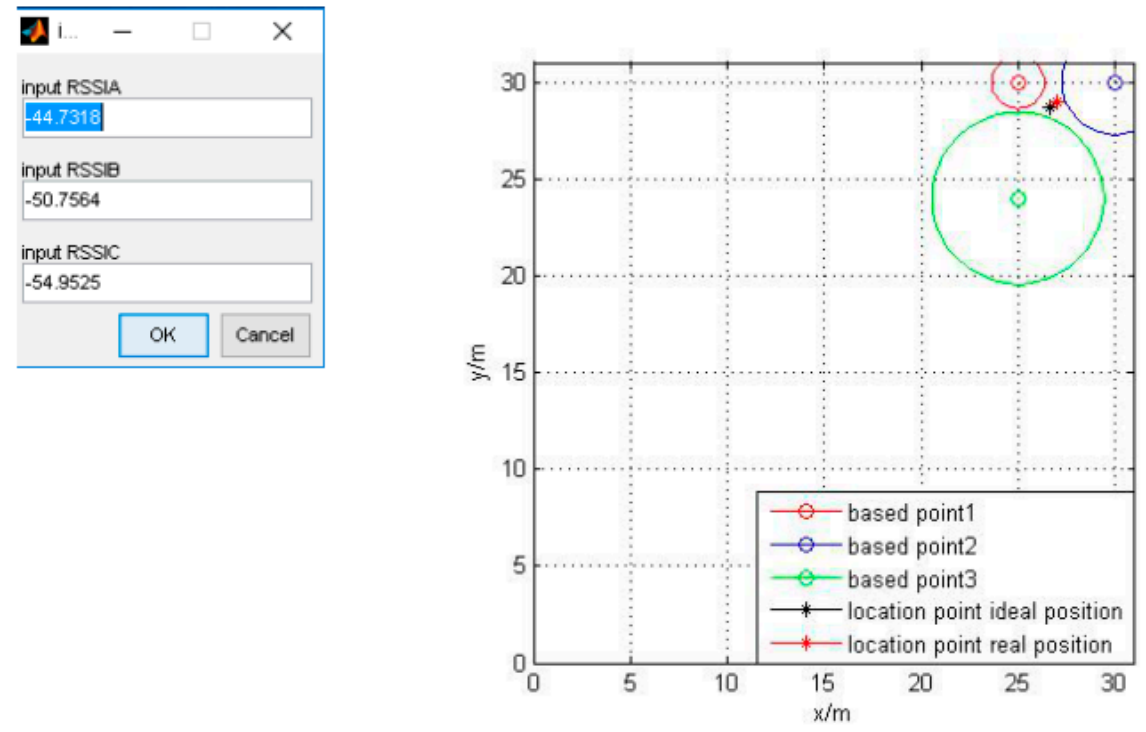

Figure 12. Simulation result when the RSSI values are $-44.7318,-50.7564$, and $-54.9525(\mathrm{dBm})$ for the three points $(a, b$, and $c)$.

Figure 5 depicts the result of the localization computation with respect to the three provided RSSI values of $-50.0537,-55.7224$, and $-58.5564(\mathrm{dBm})$, respectively. From Figure 5, we recognize that the error is $0.4438(\mathrm{~m})$ between the location point of ideal and real position.

Figure 6 shows the result of the localization computation with respect to the three provided RSSI values of $-43.1889,-56.8906$, and $-53.8736(\mathrm{dBm})$, respectively. From Figure 6, we recognize that the error is $0.9021(\mathrm{~m})$ between the location point of ideal and real position.

Figure 7 shows the result of the localization computation with respect to the three provided RSSI values of $-54.1075,-52.4424$, and $-58.2356(\mathrm{dBm})$, respectively. From Figure 7 , we recognize that the error is $0.5759(\mathrm{~m})$ between the location point of ideal and real position.

Figure 8 shows the result of the localization computation with respect to the three provided RSSI values of $-50.9142,-51.1982$, and $-58.7488(\mathrm{dBm})$, respectively. From Figure 8 , we recognize that the error is $0.4904(\mathrm{~m})$ between the location point of ideal and real position.

Figure 9 shows the result of the localization computation with respect to the three provided RSSI values of $-42.3353,-49.481$, and $-57.7724(\mathrm{dBm})$, respectively. From Figure 9, we recognize that the error is $0.3905(\mathrm{~m})$ between the location point of ideal and real position.

Figure 10 shows the result of the localization computation with respect to the three provided RSSI values of $-45.1862,-55.7421$, and $-58.1185(\mathrm{dBm})$ for respectively. From Figure 10, we recognize that the error is $0.4123(\mathrm{~m})$ between the location point of ideal and real position.

Figure 11 shows the result of the localization computation with respect to the three provided RSSI values of $-38.4322,-50.0492$, and $-58.5565(\mathrm{dBm})$, respectively. From Figure 11, we recognize that the error is $0.4314(\mathrm{~m})$ between the location point of ideal and real position.

Figure 12 shows the result of the localization computation with respect to the three provided RSSI values of $-44.7318,-50.7564$, and $-54.9525(\mathrm{dBm})$, respectively. From Figure 12, we recognize that the error is $0.4610(\mathrm{~m})$ between the location point of ideal and real position.

Figure 13 and Table 2 depict the error result between the ideal point and the estimated point when this paper performs eight calculations from Figure 5 to Figure 12. From Figure 13, we recognize that the maximum error occurs in Figure 6 which is $0.9021(\mathrm{~m})$. 


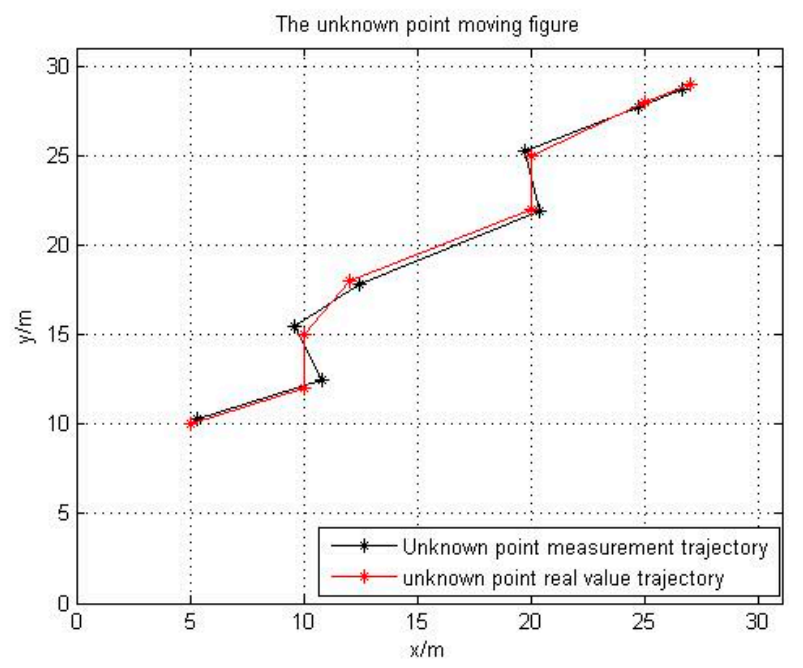

Figure 13. Error result between the ideal point and the measured (computed) point.

Table 2. RMS error result between the ideal point and the measured (computed) point.

\begin{tabular}{ccccc}
\hline Number & RSSI A $\mathbf{( d B m})$ & RSSI B $\mathbf{( d B m )}$ & RSSI C (dBm) & RMS Error $(\mathbf{m})$ \\
\hline Figure 5 & -50.0537 & -55.7224 & -58.5564 & \\
Figure 6 & -43.1889 & -56.8906 & -53.8736 & \\
Figure 7 & -54.1075 & -52.4424 & -58.2356 & \\
Figure 8 & -50.9142 & -51.1982 & -58.7488 & 0.536 \\
Figure 9 & -42.3353 & -49.481 & -57.7724 & \\
Figure 10 & -45.1862 & -55.7421 & -56.1185 & \\
Figure 11 & -38.4322 & -50.0492 & -56.5565 & \\
Figure 12 & -44.7318 & -50.7564 & -54.9525 & \\
\hline
\end{tabular}

From Table 2, we know the RMS error is $0.536(\mathrm{~m})$.

\section{Experimental Device and Result}

This section describes the experimental device, and this paper also shows the results for RSSI algorithm for real hardware system. In order to apply RSSI algorithm to localization to robot, IoT, and tracing location of each nursing home patient, Bluetooth low-energy (BLE) transmitter and receiver need to be activated, and beacon gateway. The BLE transmitter and receiver, and beacon gateway, are shown in Figures 14-16, respectively.

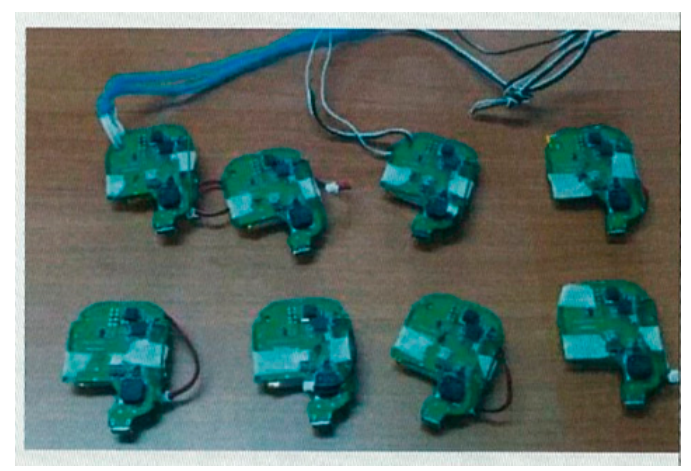

Figure 14. Hardware of Bluetooth low-energy (BLE) transmitter. 


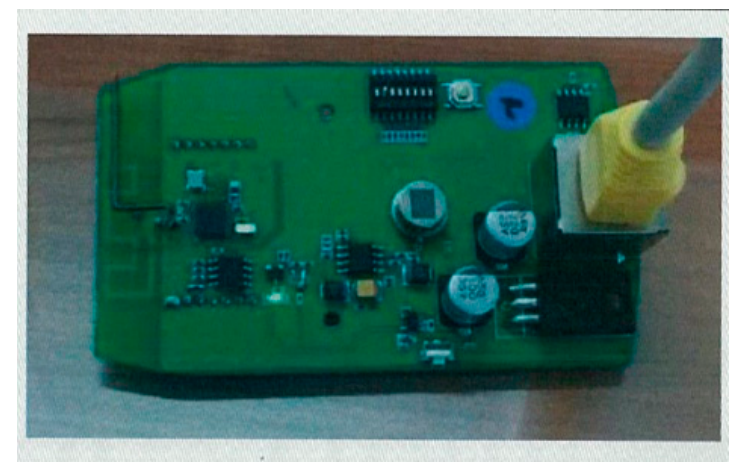

Figure 15. Hardware of BLE receiver, and beacon gateway.

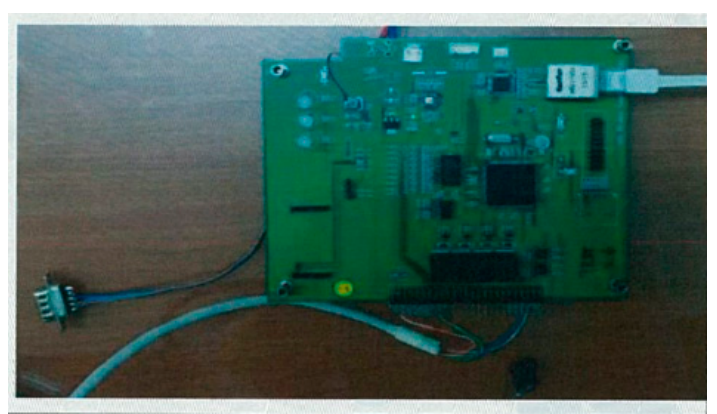

Figure 16. Hardware of beacon gateway.

Figure 17 shows the concept of communication of BLE transmitter and receiver, the beacon gateway, received data transmission, and echo data transmission path.

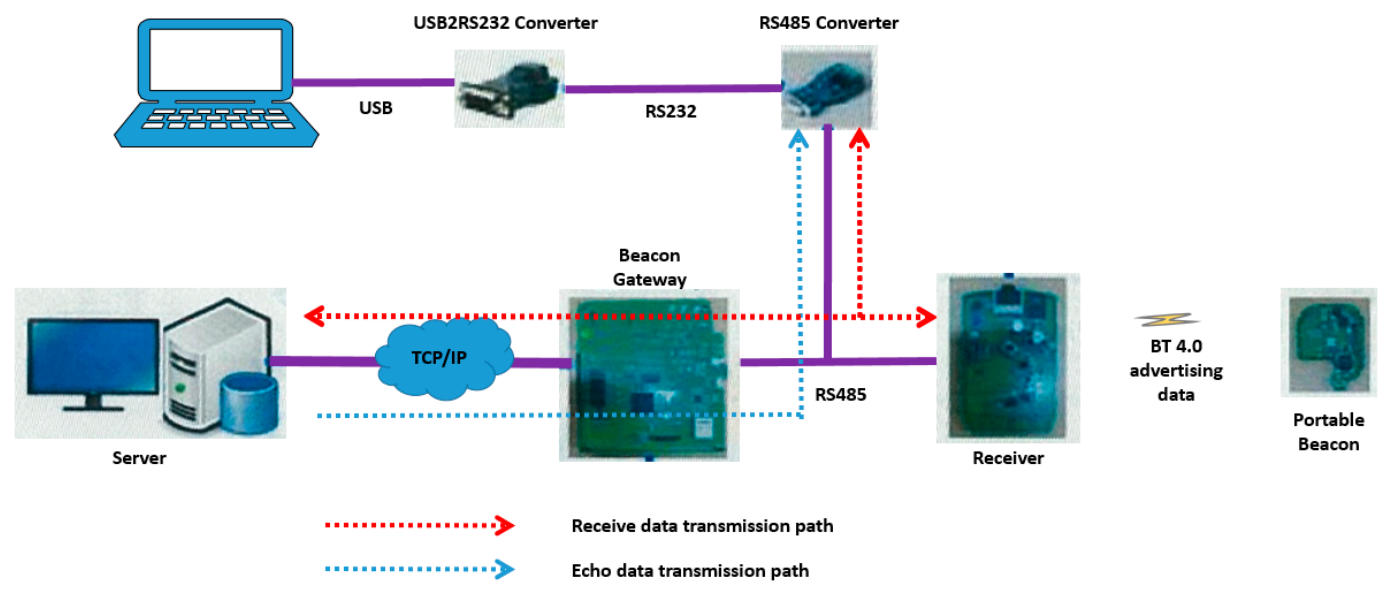

Figure 17. Concept of configuration for hardware communication.

To test for communication between using BLE transmitter and receiver, beacon gateway, and, notebook, this paper has to establish configuration of testing system. The testing system consists of BLE transmitter and receiver; beacon gateway; notebook; and communication equipment such as USB-RS232 converter (CI-202US/ALL, Centos, Taiwan) and RS 485 converter (TCC-80, MOXA, Taiwan), as shown in Figure 18. 


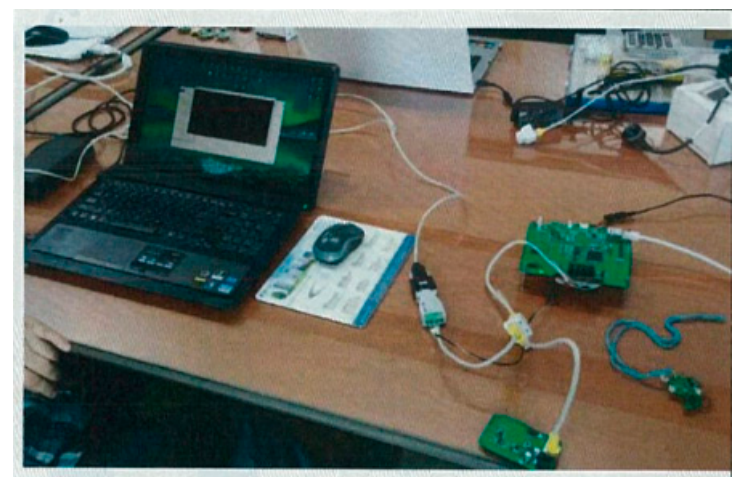

Figure 18. Configuration of testing device for RSSI.

To apply RSSI algorithm in real space, this paper configures BLE receiver, as shown in Figure 19. The BLE receiver designed one receiver that could receive eight signals from hand-held BLE transmitter.

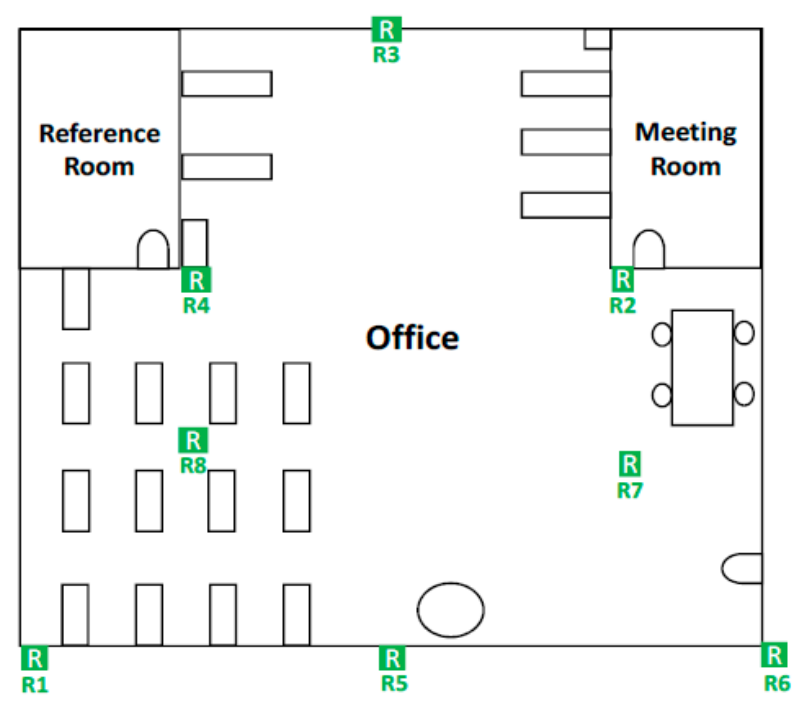

Figure 19. Configuration of testing device for BLE receiver.

From Figures 18 and 19, the localization of robot, IoT, and tracing location of each patient by using RSSI algorithm can be tested, which are proposed in Section 3. Section 3 deals with computer simulation, and it assumes the area size is $30 \mathrm{~m} \times 30 \mathrm{~m}$. However, the experimental device applies in $20 \mathrm{~m} \times 20 \mathrm{~m}$ because it cannot find such a size indoors. Figure 20 depicts the attached receivers in various places such as wall and ceiling.

Figures 18-20 show the test access (response) speed between hand-held BLE transmitter and server, hand-held BLE transmitter and beacon gateway, and DB server, respectively. Throughout these tests, the results were $60(\mathrm{~ms}), 50(\mathrm{~ms})$ and maximum $16(\mathrm{~ms})$ for access (response) speed between hand-held BLE transmitter and server, hand-held BLE transmitter, and beacon gateway, and DB server, respectively. Table 3 represents the test items, references, and their results. 


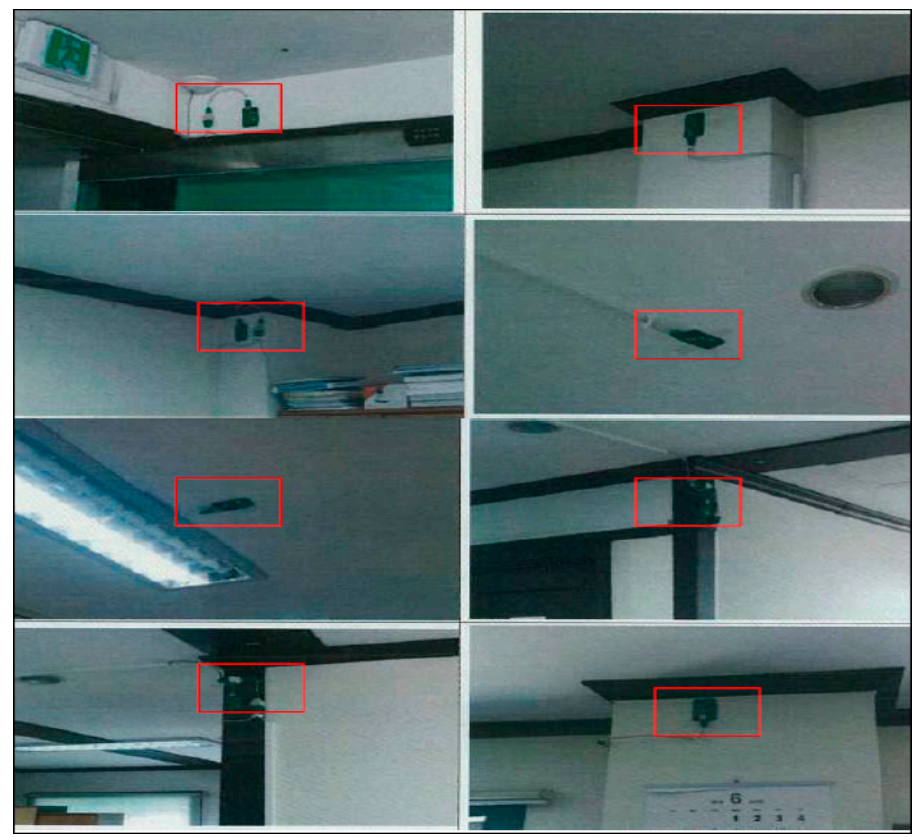

Figure 20. Configuration of test.

Table 3. Test item, reference, and their results.

\begin{tabular}{ccc}
\hline Test Item & Reference & Result \\
\hline $\begin{array}{c}\text { Access (response) speed between hand-held BLE transmitter and } \\
\text { server }\end{array}$ & $800(\mathrm{~ms})$ & $60(\mathrm{~ms})$ \\
\hline $\begin{array}{c}\text { Access (response) speed between hand-held BLE transmitter and } \\
\text { beacon gateway }\end{array}$ & $100(\mathrm{~ms})$ & $50(\mathrm{~ms})$ \\
\hline Access (response) speed for DB server & $20(\mathrm{~ms})$ & Maximum 16 (ms) \\
\hline
\end{tabular}

This paper estimates the localization and localization error between BLE transmitter and receiver by using RSSI algorithm that is presented in Section 3. In this paper, transmitter and receiver are set at laboratory with coordinate values for $x$-axis and $y$-axis as pixels. Here, one pixel is $1.5 \times 10^{-2}(\mathrm{~m})$.

\subsection{Case 1}

This paper sets at A and R2 for the transmitter and receiver, respectively, and measures the length between A and R2 by using a tapeline, which is $1.89(\mathrm{~m})$, as shown in Figure 21.
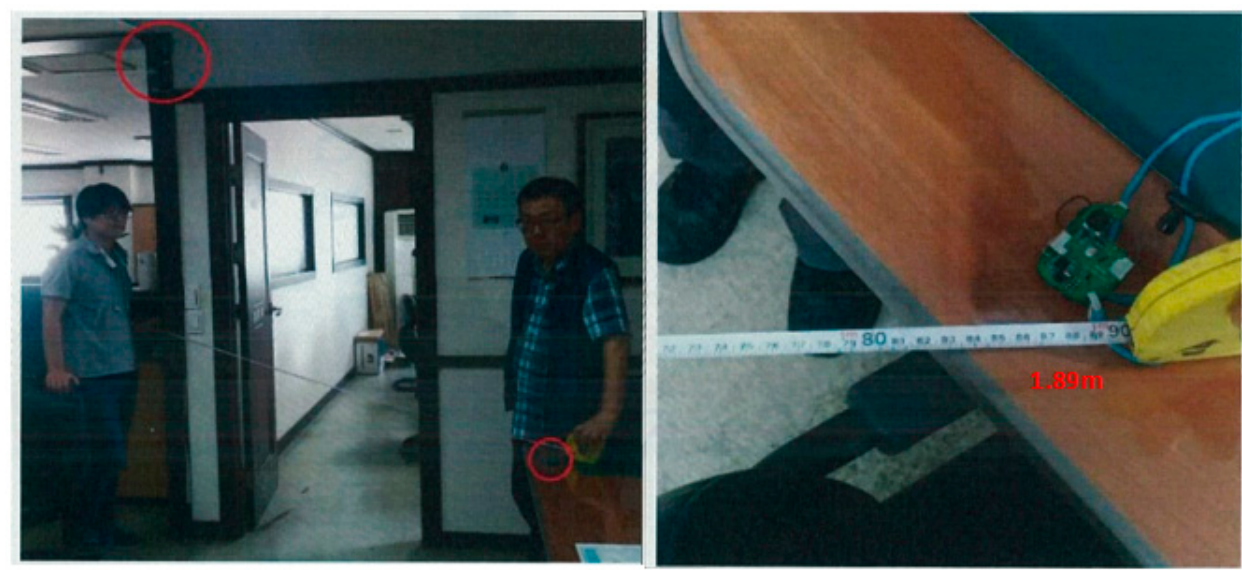

Figure 21. Location A and R2, and real distance between A and R2. 
Coordination of A point and R2 point as pixels results in $(807,698)$ and $(787,614)$, as shown in Figure 22.
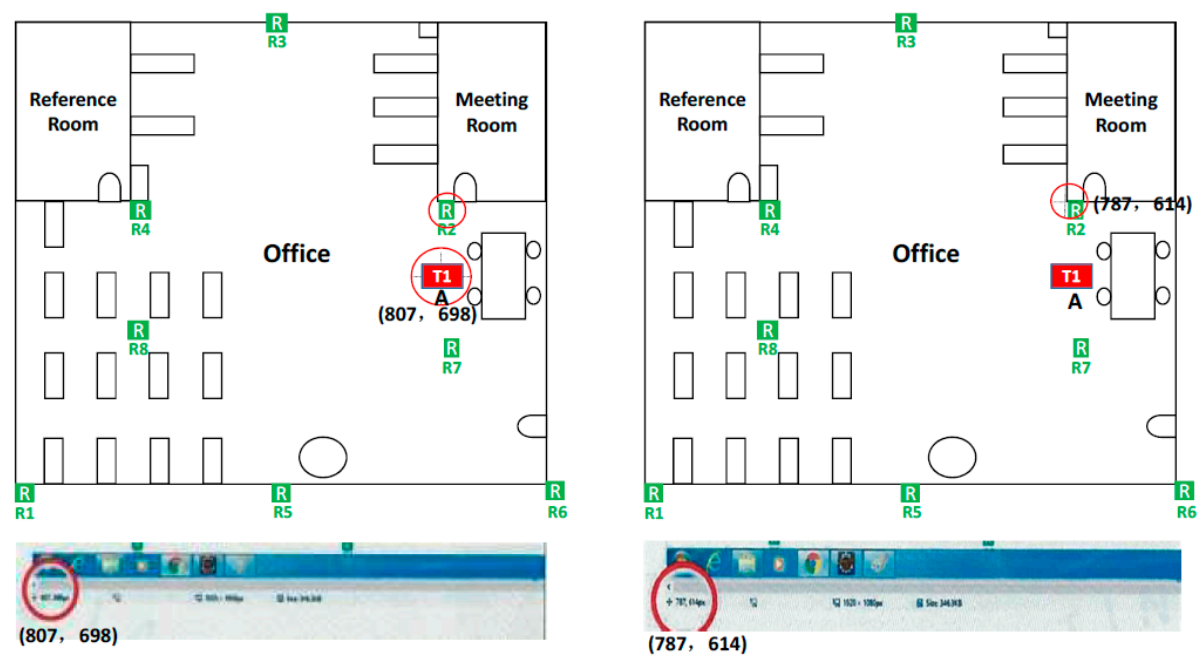

Figure 22. Coordination of A and R2.

From Figure 22, the coordination difference between A point and R2 point can be calculated, as follows:

$$
\text { Difference of A-R2 }=(807,698)-(787,614)=(20,84) \text {; }
$$

Hence, the distance of A-R2 from Equation (11) can be calculated;

$$
\text { Pixel distance of A-R2 }=\sqrt{20^{2}+84^{2}}=86.4 ;
$$

From Equation (12), the estimation of distance of A-R2 when multiplying $1.5 \times 10^{-2}(\mathrm{~m}) \mathrm{can}$ be calculated;

$$
\text { Estimation distance }=86.4 \times 1.5 \times 10^{-2}=1.296(\mathrm{~m}) ;
$$

An error between real distance and estimate distance like Equation (14) can be calculated;

$$
\text { Error }=1.89-1.296(\mathrm{~m})=0.594(\mathrm{~m}) \text {. }
$$

\subsection{Case 2}

This paper sets B and R4 as transmitter and receiver. It performs the testing with same method of case1 and gets $2.50(\mathrm{~m})$, as shown in Figure 23.

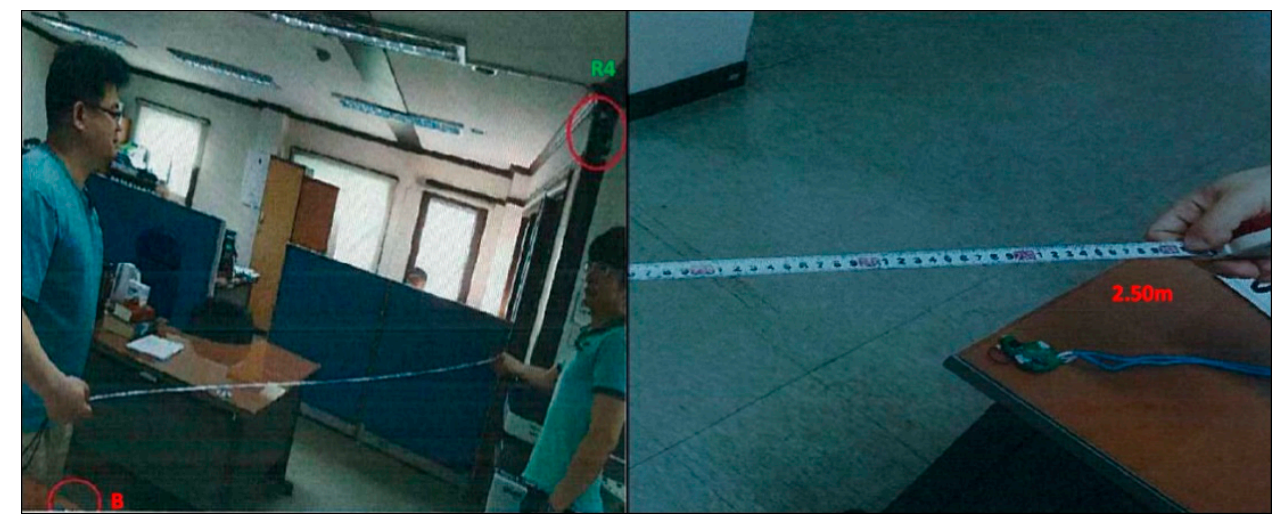

Figure 23. Location B and R4, and real distance between B and R4. 
Coordination of A point and R2 point as pixel gets $(447,758)$ and $(406,608)$, as shown in Figure 24.

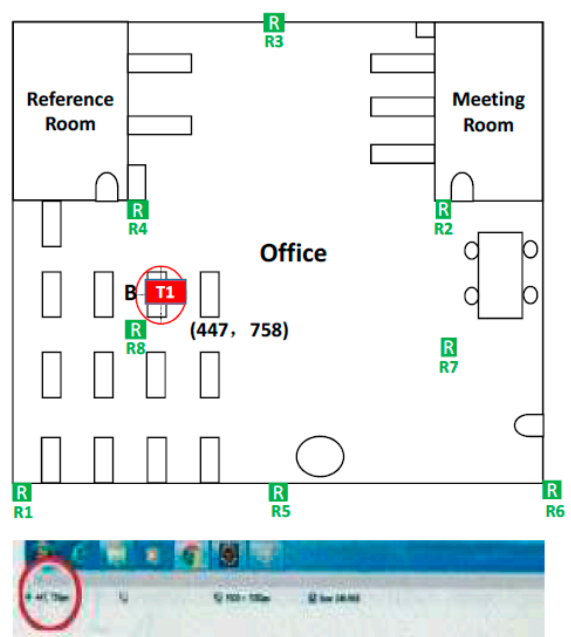

(447, 758)

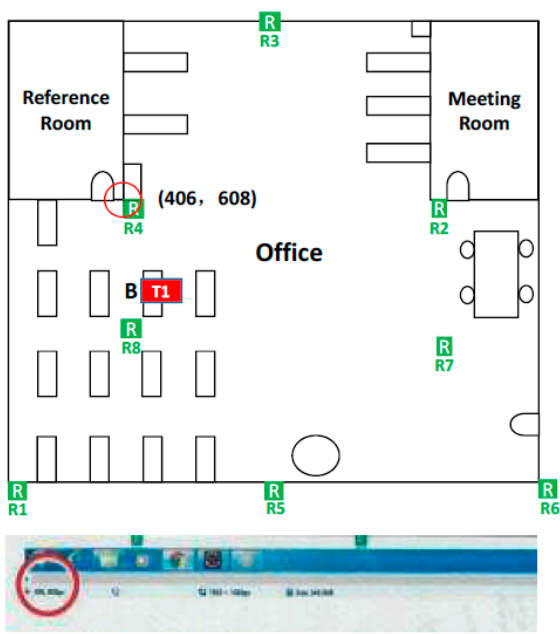

$(406,608)$

Figure 24. Coordination of B and R4.

From Figure 24, the coordination difference between B point and R4 point like case 1 in Section 4.1 can be calculated;

$$
\text { Difference of B-R4 = }(447,758)-(406,608)=(41,150) \text {; }
$$

Hence, it can calculate distance of B-R4 from Equation (16);

$$
\text { Pixel distance of B-R4 }=\sqrt{41^{2}+150^{2}}=155.5 ;
$$

From Equation (16), estimation of distance of B-R4 when multiplying $1.5 \times 10^{-2}(\mathrm{~m})$ can be calculated;

$$
\text { Estimation distance }=155.5 \times 1.5 \times 10^{-2}=2.3325(\mathrm{~m}) ;
$$

Ann error between real distance and estimate distance like Equation (18) can be calculated;

$$
\text { Error }=2.50-2.3325=0.1675(\mathrm{~m}) ;
$$

\begin{tabular}{|c|c|c|c|c|c|c|c|}
\hline Number & $\begin{array}{c}\text { A Node } \\
\text { Coordination }\end{array}$ & $\begin{array}{c}\text { B Node } \\
\text { Coordination }\end{array}$ & $\begin{array}{l}\text { Difference } \\
\text { (A-B) }\end{array}$ & $\begin{array}{c}\text { Pixel } \\
\text { Distance } \\
\text { (m) }\end{array}$ & $\begin{array}{c}\text { Real } \\
\text { Distance } \\
\text { (m) }\end{array}$ & Error (m) & $\begin{array}{c}\text { RMS } \\
\text { Error (m) }\end{array}$ \\
\hline 1 & \multirow{4}{*}{$(807,698)$} & $(787,614)$ & $(20,84)$ & 1.296 & 1.9 & 0.594 & \multirow{8}{*}{0.541} \\
\hline 2 & & $(615,250)$ & $(192,448)$ & 7.311 & 8.3 & 0.788 & \\
\hline 3 & & $(410,300)$ & $(397,398)$ & 8.432 & 9.0 & 0.567 & \\
\hline 4 & & $(452,480)$ & $(355,218)$ & 6.248 & 6.8 & 0.655 & \\
\hline 5 & \multirow{4}{*}{$(447,758)$} & $(406,608)$ & $(41,150)$ & 2.325 & 2.5 & 0.167 & \\
\hline 6 & & $(154,660)$ & $(293,98)$ & 4.634 & 4.8 & 0.165 & \\
\hline 7 & & $(260,520)$ & $(187,238)$ & 4.540 & 4.9 & 0.359 & \\
\hline 8 & & $(280,450)$ & $(167,308)$ & 5.255 & 5.9 & 0.744 & \\
\hline
\end{tabular}

From above experimental process, this paper can calculate root mean square (RMS) error for measurement. Table 4 represents result of RMS error for 8 times.

Table 4. RMS error result for real field. 
Table 4 shows that RMS error is $0.541(\mathrm{~m})$, calculated 8 times. However, when it applies 100 times, RMS error is $0.545(\mathrm{~m})$. Thus, the difference of RMS error between computer simulation and real experimental data is very small. Additionally, the RMS error of computer simulation and real experimental data implemented in this paper is smaller than other RSSI method presented in Table 1. The difference of RMS errors for RSSI method between results of Table 1 [19] shown by computer simulation and proposed method by real experimental environment, is due to strength of power, different interference status, and application a slightly different calculation method of distance between BLE transmitter and receiver.

\section{Conclusion}

This paper proposed the application of a robust ranging method that can be applied in robots, IoT, and especially in the tracing location of each nursing home patient where the RSSI method is used. This paper shows the results of the measured point from the application of the trilateral technique, and it also represents the results of the error distance between the ideal point and the measured point. The error between the ideal point and the estimated point occurs when this paper performs eight calculations. The computer simulation result represents the RMS error that is less than $0.536(\mathrm{~m})$. This paper presents a real experimental system with a hardware system and its results of measuring an RMS error that is less than $0.545(\mathrm{~m})$. Therefore, when this paper applies the BLE system that applies RSSI in robots and IoT to estimate localization, it can apply the presented system with an error within 0.55 (m).

The main difference of the RMS error between computer simulation and the experimental system is due to the difference of the wireless electric wave environment. Even though this study considers the exact wireless electric wave environment in the computer simulation, it is not difficult to reflect upon the tracing location of each patient in real wireless electric wave environments in the real fields such as hospital and nursing homes.

Funding: This research received no external funding.

Conflicts of Interest: The authors declare no conflict of interest.

\section{References}

1. Gao, J.; Gao, X.; Zhu, W.; Zhu, J.; Wei, B. Mobile robot room location system design and research. Inf. Comput. Autom. 2008, 3, 923-926.

2. Mohareri, O.; Rad, A.B. Vision-based location positioning system VIA augmented reality: An application in humanoid robot navigation. Inter. J. Humanoid Robo. 2013, 10, 1350019. [CrossRef]

3. Liu, Y.; Yang, J.; Wu, Z. Ubiquitous and cooperation network robot system within a service framework. Inter. J. Humanoid Robo. 2011, 8, 147-167. [CrossRef]

4. Yang, T.H.; Yi, S.; Qi, D.; Tao, H.; Xu, C.R. The Locating method by measuring its acceleration for in-pipelines inspection robots. Inf. Comput. Autom. 2008, 3, 931-934.

5. Shon, Y. Scientometric, Analysis for the IOT of service oriented and next generation smart device. J. Kor. Inst. Elect. Comm. Sci. 2015, 10, 721-728. [CrossRef]

6. Hu, L.; Jiang, J.; Zhou, J. Environment observation system based on semantics in the internet of things. J. Networks 2013, 8, 2721-2727. [CrossRef]

7. Karl, H.; Willing, A. Protocols and Architectures for Wireless Sensor Networks; John Wiley \& Sons, Inc.: Hoboken, NJ, USA, 2005.

8. Akyildiz, I.F. Wireless sensor networks: A survey. Comput. Networks 2002, 38, 393-422. [CrossRef]

9. Wang, C.; Xiao, L. Sensor localization under limited measurement capabilities. IEEE Network 2007, 21, 16-23. [CrossRef]

10. Sairah, N.; Ko, N.Y. Analysis of indoor robot localization using ultrasonic sensors. Int. J. Fuzzy Logic Intell. Syst. 2014, 14, 41-48.

11. Gabriel, H.; Fay, H.; Reinhard, K. Landmark initialization for unscented Kalman filter sensor fusion in monocular camera localization. Int. J. Fuzzy Logic Intell. Syst. 2013, 13, 1-10. 
12. Mao, G.; Fidan, B.; Brian, D.; Anderson, O. Wireless sensor network localization techniques. Comput. Networks 2007, 51, 2529-2553. [CrossRef]

13. Bram, D.; Stefan, D.; Havinga, P. Wireless Sensor Networks: Range-based Localization in Mobile Sensor Networks; EWSN: Zurich, Switzerland, 2006; pp. 164-179.

14. Mazur, V.; Williams, E.; Boldi, R.; Maier, L.; Proctor, D.E. Initial comparison of lightning mapping with operational time-of-arrival and interferometric systems. J. Geophys. Res. D 1997, 102, 11071-11085. [CrossRef]

15. Pulgarín, J.; Younes, C.; del Río, D. Electromagnetic fields generated by lightning channels with tortuosity and its effect on the time-of-arrival technique. In Proceedings of the 12th International Symposium on Lightning Protection, Belo Horizonte, Brazil, 7-11 October 2013; pp. 140-144.

16. Salimi, B.; Abdul-Malek, Z.; Mehranzamir, K.; Mashak, S.V.; Afrouzi, H.N. Localized single-station lightning detection by using TOA method. J. Teknologi 2013, 64, 73-77.

17. Bekcibasi, U.; Tenruh, M. Increasing RSSI localization accuracy with distance reference anchor in wireless sensor networks. Acta Polytech. Hungarica 2014, 11, 103-120.

18. Alippi, C.; Vanini, G. A RSSI-based and calibrated centralized localization technique for wireless sensor networks. In Proceedings of the Fourth Annual IEEE International Conference on Pervasive Computing and Communications Workshops, Pisa, Italy, 13-17 March 2006; pp. 301-306.

19. Pradhan, S.; Bae, Y.; Pyun, J.Y.; Ko, N.Y.; Hwang, S.S. Hybrid TOA Trilateration Algorithm Based on Line Intersection and Comparison Approach of Intersection Distances. Energies 2019, 12, 1668. [CrossRef]

20. Wang, J.; Urriza, P.; Han, Y.; Cabric, D. Weighted Centroid Localization Algorithm: Theoretical Analysis and Distributed Implementation. IEEE Trans. Wirel. Commun. 2011, 10, 3403-3413. [CrossRef]

21. Roberts, R. TDOA localization techniques, working group for wireless personal area networks (WPANs). 2004. Available online: https://www.enriquedans.com/wp-content/uploads/2013/03/TDOA-localizationtechniques.pdf (accessed on 7 June 2019).

22. Kułakowski, P.; Vales-Alonso, J.; Egea Lopez, E.; Ludwin, W.; García-Haro, J. Angle-of-arrival localization based on antenna arrays for wireless sensor networks. Comput. Electri. Eng. 2010, 36, 1181-1186. [CrossRef]

23. Scherhaufl, M.; Pichler, M.; Ziroff, A.; Stelzer, A. Phase-of-arrival-based localization of passive UHF RFID tags. In Proceedings of the IEEE MTT-S International Microwave Symposium Digest (MTT), Seattle, WA, USA, 2-7 June 2013; pp. 1-3.

24. Han, G.; Xu, H.H.; Duong, T.Q.; Jiang, J.F.; Hara, T. Localization algorithms of Wireless Sensor Networks: A survey. Telecommun. Syst. 2013, 52, 2419-2436. [CrossRef]

25. He, T.; Huang, C.; Blum, B.-M.; Stankovic, J.A.; Abdelzaher, T. Range-free localization schemes for large scale sensor networks. In Proceedings of the 9th annual international conference on Mobile computing and networking, San Diego, CA, USA, 14-19 September 2003; pp. 81-95.

26. Paraxnvir, B.; Venkata, P.N. RADAR: An inbuilding RF-based user location and tracking system. In Proceedings of the IEEE INFOCOM, Tel Aviv, Israel, 26-30 March 2000; pp. 775-784.

27. Thomas, F.; Ros, L. Revisiting trilateration for robot localization. IEEE Trans. Rob. 2005, 21, 93-101. [CrossRef]

28. Lau, E.-E.-L.; Chung, W.Y. Enhanced RSSI-Based Real-Time User Location Tracking System for Indoor and Outdoor Environments. In Proceedings of the International Conference on Convergence Information Technology, Gyeongju, South Korea, 21-23 November 2007; pp. 1213-1218.

29. Shuo, S.; Hao, S.; Yang, S. Design of an experimental indoor position system based on RSSI. In Proceedings of the 2nd International Conference on Information Science and Engineering, Hangzhou, China, 4-6 December 2010; pp. 1989-1992.

30. Peng, W.W.; Xin, W. Research on robot indoor localization method based on wireless sensor network. In Proceedings of the International Conference on Advances in Mechanical Engineering and Industrial Informatics, Zhengzhou, China, 11-12 April 2015; pp. 1025-1040.

31. Ning, G.; Gang, W.Z.; Gang, S.K. Research on Indoor Positioning Algorithm Based on Trilateral Positioning and Taylor Series Expansion. In Proceedings of the International Conference on Computational Modeling, Simulation and Applied Mathematics, Bangkok, Thailand, 24-25 July 2016.

32. Friis, H.T. A note on a simple transmission formula. Proc. IRE. 1946, 34, 254-256. [CrossRef]

(C) 2019 by the author. Licensee MDPI, Basel, Switzerland. This article is an open access article distributed under the terms and conditions of the Creative Commons Attribution (CC BY) license (http://creativecommons.org/licenses/by/4.0/). 